\title{
Área de (Des) proteção ambiental Serra do Lajeado - TO: DEGRADAÇÃO AMBIENTAL IDENTIFICADA POR ANÁLISE DE COBERTURA VEGETAL E CRIMES REGISTRADOS NO PERÍODO DE 2001 A 2016
}

\author{
Adila Maria Taveira de Lima*, Adson Gomes de Ataídes, Eloísa Paula Bispo de Sousa, Talita \\ Mucari, Carla Simone Seibert
}

Programa de Pós-Graduação em Ciências do Ambiente - Universidade Federal do Tocantins, Palmas - TO, Brasil.

*Autor para correspondência: adm.adila@gmail.com

Recebido em 15 de fevereiro de 2017. Aceito em 30 de março de 2018. Publicado em 14 de abril de 2018.

\begin{abstract}
REsumo - Áreas de proteção ambiental - APAs são estabelecidas com o objetivo de preservação da biodiversidade, restringindo o grau de interferência humana sob medidas legais, e são consideradas uma das estratégias mais eficazes para a conservação dos recursos naturais. A APA Serra do Lajeado está localizada ao centro do Estado do Tocantins, foi criada em 1997, ocupando inicialmente uma área de 121.415,5ha, inserida em quatro municípios: Aparecida do Rio Negro, Tocantínia, Lajeado e Palmas. Neste contexto, o presente trabalho buscou verificar a conservação da APA Serra do Lajeado, no período de 2001 a 2016, por meio do levantamento de crimes ambientais ocorridos na área abrangente da APA, coletados junto ao órgão ambiental estadual, com estudo e análises das imagens de sensoriamento remoto. Nesta última fase procedeu-se com as interpretações visuais e posteriormente classificações digitais supervisionadas para identificar "área desmatada" e "área remanescente". O trabalho demonstrou que ocorreram 844 crimes ambientais e uma supressão de aproximadamente $11 \%$ da cobertura vegetal. Assim, houve comprometimento da cobertura vegetal da APA, principalmente em Aparecida do Rio Negro, onde há atividade vinculada à produção de grãos e agropecuária.
\end{abstract}

Palavras-chave: Área de Proteça Ambiental; Desmatamento; Sensorlamento Remoto; Crime Ambiental.

SERra do LajEAdo - TO, AREA OF ENVIRONMENTAL (DE)PROTECTION: ENVIRONMENTAL DEGRADATION IDENTIFIED BY PLANT COVER ANALYSIS AND CRIMES RECORDED FROM 2001 TO 2016.

Aвstract - Areas of environmental protection - AEPs - are established with the objective of preserving biodiversity, restricting the degree of human interference under legal measures and are considered one of the most effective strategies for the conservation of natural resources. AEP Serra do Lajeado was created in 1997 in the center of the Tocantins State on an area of 121,415.5 Ha, it is located in four municipalities: Aparecida do Rio Negro, Tocantínia, Lajeado and Palmas. In this context, the present study sought to verify the conservation of Serra do Lajeado AEP, from 2001 to 2016 , by means of the survey of environmental crimes occurred in the broad area of the AEP. The data was collected in cooperation with the state environmental agency and by studying and analyzing of the remote sensing images. In this last phase we were performing the visual interpretations and, later, supervised digital classifications in order to identify "deforested area" and "remaining area". The study showed that 844 environmental crimes occurred and that there was approximately $11 \%$ of the vegetal cover suppression. Thus, the vegetation cover of the AEP was ???, mainly in the area of Aparecida do Rio Negro, where grain production and agriculture linked activity are present.

Keywords: Entironmental Protection Area; Deforestation; Remote Sensing; Entironmental Crime.

ÁreA de (DES)PROTECCIÓN AMBIENTAL SERRA do LAJEAdo - TO: DEGRADACIÓN AMBIENTAL IDENTIFICADA POR ANÁLISIS 
DE COBERTURA VEgETAL Y CRÍMENES REgISTRADOS EN EL PERÍOdo DE 2001 A 2016.

RESumen - Las áreas de protección ambiental - APAs - se establecen con el objetivo de preservar la biodiversidad, restringiendo el grado de interferencia humana bajo medidas legales y se consideran una de las estrategias más eficaces para la conservación de los recursos naturales. La APA Serra do Lajeado está ubicada en el centro del Estado de Tocantins, fue creada en 1997, ocupando inicialmente un área de 121.415,5ha, insertada en cuatro municipios: Aparecida del Río Negro, Tocantínia, Lajeado y Palmas. En este contexto, el presente trabajo buscó verificar la conservación de la APA Serra do Lajeado, en el período de 2001 a 2016, por medio del levantamiento de crímenes ambientales ocurridos en el área amplia de la APA, recogidos junto al órgano ambiental provincial, con estudio y análisis de las imágenes de detección remota. En esta última fase se procedió con las interpretaciones visuales y posteriormente clasificaciones digitales supervisadas para identificar "área deforestada” y "área remanente”. El trabajo demostró que ocurrieron 844 crímenes ambientales y una supresión de aproximadamente el 11\% de la cobertura vegetal. Así, hubo comprometimiento de la cobertura vegetal de la APA, principalmente en Aparecida del Río Negro, donde hay actividad vinculada a la producción de granos y agropecuaria.

Palabras clave: Área de Protección Ambiental; Deforestación; Detección Remota; Crimen Ambiental.

\section{INTRODUÇÃO}

O processo de ocupação de áreas protegidas nos maiores biomas brasileiros, cerrado e amazônico, acentuou-se nos últimos anos, e tem sido marcado pelo desmatamento intenso, degradação dos recursos naturais e conflitos sociais, ocasionando perda significativa das áreas (Medeiros 2006; Verissimo et al. 2011). Dada sua relevância e importância no contexto ecológico mundial, muitos pesquisadores e especialistas se preocupam com esta questão, propondo medidas e políticas públicas de intervenção, a fim de associar desenvolvimento econômico e sustentabilidade ambiental.

A preservação da biodiversidade efetiva-se conservando comunidades, para tanto se estabelece áreas de proteção, nas quais o grau de interferência humana é restringido por lei. Determinam-se medidas legais para proteger ou regular o uso da terra, instrumentos fundamentais que buscam resguardar a integridade dos ecossistemas, "não somente por serem depositários dos recursos biológicos, mas também por constituírem sítios nos quais a pesquisa e a utilização sustentável desses recursos podem ser desenvolvidas" (Medeiros 2006).

Segundo o Ministério do Meio Ambiente - MMA, uma das formas de garantir a conservação da diversidade biológica de um país é o estabelecimento de um sistema de áreas protegidas que incluem as áreas de proteção permanente, as reservas legais, as reservas indígenas e as unidades de conservação. Esse sistema de proteção é considerado eficaz para resguardar a integridade dos ecossistemas, a biodiversidade e os serviços ambientais associados, tais como, a conservação do solo e proteção das bacias hidrográficas, a polinização, o ciclo de nutrientes, o equilíbrio climático, entre outros (MMA 2016).

A necessidade de se criar e manter unidades de conservação no Brasil é clara na Constituição Federal, artigo 225, parágrafo $1^{\circ}$, inciso III, o qual incumbe ao poder público: “definir, em todas as unidades da Federação, espaços territoriais e seus componentes a serem especialmente protegidos, sendo a alteração e a supressão permitidas somente através de lei, vedada qualquer utilização que comprometa a integridade dos atributos que justifiquem a sua proteção" (Brasil 1988).

Com o propósito de estabelecer critérios e normas para a criação, implantação e gestão das unidades de conservação, o governo brasileiro no ano 2000, instituiu o Sistema Nacional de Unidades de Conservação da 
Natureza - SNUC, por meio da lei 9.985/2000 (Brasil 2000a). O SNUC é formado pelo conjunto das unidades de conservação federais, estaduais e municipais e preconiza alguns instrumentos adicionais para auxiliar na concretização dos objetivos da manutenção das Unidades de Conservação (UC), além disso, estabeleceu mecanismos que regulamentam a participação da sociedade na gestão das UC, potencializando a relação entre o Estado, os cidadãos e o meio ambiente (MMA 2016). De acordo com Carregosa et al. (2015) essa lei introduziu modificações importantes na política de criação e gestão de UCs no país, contribuindo para a superação de equívocos cometidos no processo histórico de implantação dessas áreas, centrado na criação de unidades de caráter restritivo à ocupação humana.

As Unidades de Conservação são áreas instituídas e geridas pelo poder público. De acordo com o SNUC, são definidas como "espaços territoriais e seus recursos ambientais, incluindo as águas jurisdicionais com características naturais relevantes, legalmente instituídos pelo poder público, com o objetivo de conservação e limites definidos sob regime especial de administração ao qual se aplica garantias adequadas de proteção" (Brasil 2000a). Teixeira e Venticinque (2014) ressaltam que a criação de áreas legalmente protegidas sob a forma de Unidades de Conservação - UCs, tem se tornado uma estratégia fundamental para a conservação dos recursos naturais.

As Unidades de Conservação (UCs) classificam-se em: (1) Unidades de Proteção Integral, nas quais é permitido o uso indireto dos recursos naturais, em pesquisa científica, turismo e educação ambiental. Nestas estão inclusas as seguintes categorias: Estação Ecológica, Reserva Biológica, Parques, Monumento Natural, Refúgio de Vida Silvestre; e (2) Unidades de Uso Sustentável, são aquelas destinadas tanto a conservação da biodiversidade como a extração racional de recursos naturais, sendo permitido o turismo, educação ambiental e a extração de produtos florestais madeireiros e não madeireiros, com base no uso sustentável e no plano de manejo da unidade (Brasil 2000a; Verissimo et al. 2011).

As Unidades de Uso Sustentável buscam compatibilizar a conservação da natureza com o uso sustentável de parcela dos seus recursos naturais e constituem: Área de Proteção Ambiental (APA), Área de Relevante Interesse Ecológico (Arie), Floresta Nacional (Flona), Reserva Extrativista (Resex), Reserva de Fauna, Reserva de Desenvolvimento Sustentável (RDS) e Reserva Particular do Patrimônio Natural (RPPN) (Brasil 2000a; Rylands e Brandon 2005).

O artigo 15, da lei no 9.985 de 18 de julho de 2000, conceitua a Área de Proteção Ambiental (APA) como área em geral extensa, com certo grau de ocupação humana, dotada de atributos abióticos, bióticos, estéticos ou culturais importantes para a qualidade de vida e o bem-estar das populações humanas, e tem como objetivos básicos proteger a diversidade biológica, disciplinar o processo de ocupação e assegurar a sustentabilidade do uso dos recursos naturais. Essa categoria de Unidade de Conservação é constituída por terras pública e privada, nas quais podem ser estabelecidas normas e restrições de uso (Brasil 2000a).

Ainda que amparadas por lei, as áreas protegidas não estão imunes a ameaças. O desmatamento, as estradas, a mineração, a exploração madeireira, a expansão agrícola, o crescimento urbano e os grandes projetos de infraestrutura, de um modo geral, impactam diretamente essas áreas protegidas, prejudicando a sua manutenção. Aliado a isso, a falta de eficácia por parte do Estado no papel fiscalizador contribui para os prejuízos na conservação dessas áreas. Dessa forma, a história do processo de produção do espaço urbano e do seu impacto sobre os recursos naturais e sobre a qualidade dos assentamentos humanos evidencia as dificuldades da articulação da temática ambiental e urbana nesse processo, deixando a proteção de áreas essenciais, diversas 
vezes, em segundo plano (Peixoto 2006).

Neste contexto, a APA Serra do Lajeado, localizada no estado do Tocantins é uma unidade de conservação de uso sustentável, que tem a finalidade principal de "garantir a conservação da fauna, da flora e do solo, proteger a qualidade das águas e as vazões mananciais da região, assegurando as condições de sobrevivência necessárias para as populações humanas das regiões circunvizinhas" (Naturatins 2005a). Diante desse cenário, busca-se identificar no presente trabalho se a APA Serra de Lajeado se mantém adequadamente aos propósitos de área sustentável, dentre as atividades permitidas e qual a proporção de área reduzida no decorrer dos anos. Para tanto, definiu-se como objetivo principal dessa pesquisa verificar a conservação da APA Serra do Lajeado, no período de 2001 a 2016. Para esse propósito, foram realizados levantamentos dos crimes ambientais registrados pelo órgão fiscalizador estadual e análise de imagens de satélite.

\section{Áreas protegidas no Brasil e a Área de Proteção Ambiental-APA Serra do Lajeado}

No Brasil, muitas iniciativas foram realizadas para implementar a política de conservação do meio ambiente. As pressões dos movimentos mundiais exigiam e discutiam a manutenção das florestas brasileiras, mas somente em 1981, com a promulgação da Lei 6.938, foi criada a Política Nacional de Meio Ambiente (PNMA), e se instituiu de fato uma forma organizada de tratar as questões ambientais. Além disso, o Art. $8^{\circ}$ da Lei n ${ }^{\circ}$ 6.902, de 27 de abril de 1981, destaca que “o Poder Executivo, quando houver relevante interesse público, poderá declarar determinadas áreas do Território Nacional como de interesse para a proteção ambiental, a fim de assegurar o bem-estar das populações humanas e conservar ou melhorar as condições ecológicas locais” (Brasil 1981). A partir daí, estabeleceu-se a junção das forças entre União, Estados e Municípios, criando-se o Sistema Nacional do Meio Ambiente - SISNAMA (Rezende 2007) e, em 1988, com a promulgação da constituição, a matéria passou a ser constitucional, proporcionando um avanço nas questões de conservação e manejo ambiental.

Com a assinatura da Convenção sobre Diversidade Biológica (CDB), realizada na Conferência das Nações Unidas sobre o Meio Ambiente e Desenvolvimento (CNUMAD), em 1992, o Brasil se comprometeu a desenvolver estratégias políticas, planos e programas nacionais para áreas protegidas, instituindo o Plano Estratégico Nacional de Áreas Protegidas (PNAP), por meio do Decreto 5.758/2006 (Brasil 2006). A Convenção sobre Diversidade Biológica conceituou o termo "áreas protegidas", como uma área delimitada geograficamente que é destinada, ou regulamentada, e administrada para alcançar objetivos específicos de conservação (Brasil 2006). Do mesmo modo, a União Internacional para Conservação da Natureza - IUCN definiu como um espaço geográfico claramente demarcado, reconhecido, dedicado e gerido para conservação da natureza, assim como dos recursos naturais e culturais associados, por meios legais ou outros meios eficazes (Dudley 2008).

De acordo com dados disponibilizados no Ministério do Meio Ambiente, o Brasil apresenta 2.041 unidades entre as esferas, federal, estadual e municipal, perfazendo uma área maior que 115 milhões de hectares de preservação. Dentre estas, 30 Unidades de Conservação estão situadas no Estado do Tocantins, abrangendo aproximadamente 14,9\% da área total do Estado, sendo que 11 são Áreas de Proteção Ambiental (APA) (MMA 2016).

Áreas de Proteção Ambiental - APAs estão localizadas estrategicamente em regiões com qualidades ambientais relevantes à conservação e disciplinam as atividades humanas de forma a proporcionar o uso sustentável dos recursos naturais e a qualidade ambiental para as comunidades locais, por meio de planos de 
manejo e zoneamento, incluindo área de proteção integral da vida silvestre. No geral, estas áreas têm atributos bióticos e abióticos, estéticos ou culturais importantes para a qualidade de vida. Essa categoria de unidade de conservação tem sido largamente adotada no Brasil, como zona tampão ou zona de amortecimento para Parques e Reservas (Kantek et al. 2009).

Nesse contexto destaca-se a APA Serra do Lajeado, unidade de conservação estadual, implantada, supervisionada, administrada e fiscalizada pelo Instituto Natureza do Tocantins, NATURATINS, cujo principal objetivo, segundo a Lei de criação da APA Serra do Lajeado, no 906 de 20 de maio de 1997, no artigo $1^{\circ}$ é garantir a conservação da fauna, da flora e do solo, proteger a qualidade das águas e as vazões mananciais da região, assegurando as condições de sobrevivência necessárias para as populações humanas das regiões circunvizinhas (Tocantins 1997).

É importante também destacar que de acordo com este instrumento regulatório, dentro dos limites da APA "Serra do Lajeado", todas as atividades ficam condicionadas à prévia autorização, por parte do Executivo Estadual, que poderá restringir ou proibir, dependendo do grau de impacto.

O SNUC (Lei 9.985/2000) determina que as unidades de conservação devam dispor de um Plano de Manejo, o qual abrange a área de conservação, sua zona de amortecimento e os corredores ecológicos, incluindo medidas com o fim de promover sua integração à vida econômica e social das comunidades vizinhas. Portanto, o plano de manejo de uma Unidade de Conservação representa importante documento técnico, no qual são estabelecidas as delimitações das áreas, métodos de gestão, fiscalização, manutenção, organização, dentre outros aspectos fundamentais para alcançar os objetivos devidos ao implementar a área de proteção (Brasil 2000a). Além disso, mecanismos de avaliação da efetividade de uso são extremamente urgentes e necessários. Teixeira e Venticinque (2014) corroboram afirmando que a "avaliação da efetividade de manejo é um instrumento de gestão de áreas protegidas indispensável, uma vez que mede a priori como as UCs estão sendo eficientes em alcançar seus objetivos de conservação".

Nesse sentido, no Plano de manejo da APA Serra do Lajeado são estabelecidas áreas de zoneamento divididas em duas categorias: Zona de Preservação e Zona de Conservação. A zona de preservação ou Serrana tem como função principal proteger os sistemas naturais existentes, considerados de alta peculiaridade ambiental e alta susceptibilidade de riscos ambientais. Destaca-se que a utilização dos recursos existentes está condicionada à observância de normas de controle rigorosas e podem ser admitidos usos moderados e autossustentáveis da biota, a exemplo de atividades turísticas controladas, tendo como objetivo maior assegurar a manutenção dos ecossistemas naturais (Naturatins 2005a).

A zona de conservação tem como função principal permitir a ocupação do território sob condições adequadas de manejo e utilização dos recursos naturais. A ocupação e uso dessas áreas devem ser compatíveis com as diferentes capacidades de suporte ambiental e estar em conformidade com a legislação vigente. Podem ser enquadradas em quatro subdivisões: a) Zona de recuperação, aquelas que têm como objetivo amortecer eventuais impactos na área-núcleo (PEL); b) Zona de uso especial refere-se a áreas que carecem de proteção pelas suas características próprias, como a potencialidade hídrica voltada ao abastecimento público, além disso, geralmente são áreas submetidas à pressão de uso e ocupação, considerando a proximidade com centros urbanos e eixos rodoviários, necessitando de monitoramento intensivo por serem passíveis de impactos ambientais (Naturatins 2005a); c) Áreas de uso extensivo são permitidas atividades relacionadas à agricultura familiar, devendo-se ajustá-las aos princípios da sustentabilidade; e d) Áreas de uso intensivo, nas quais são permitidas 
atividades agropecuárias, porém com implementação de práticas sustentáveis (Naturatins 2005a).

Para garantir a efetividade de uso sustentável e conservação das áreas de preservação, a Lei n ${ }^{\circ} 9.605$, de 12 de fevereiro de 1998, dispôs sobre as sanções penais e administrativas derivadas de condutas e atividades lesivas ao meio ambiente; tendo sido regulamentada, no que diz respeito às infrações administrativas, pelo Decreto $\mathrm{n}^{\circ}$ 6.514, de 22 de julho de 2008. É considerada infração administrativa ambiental toda ação ou omissão que viole regra jurídica de uso, gozo, promoção, proteção e recuperação do meio ambiente (Brasil 2008). O Art. 70 S $1^{\circ}$, da referida lei, destaca que são autoridades competentes para lavrar auto de infração ambiental e instaurar processo administrativo os funcionários de órgãos ambientais integrantes do Sistema Nacional de Meio Ambiente SISNAMA, designados para as atividades de fiscalização (Brasil 1998).

A apuração dessas infrações junto ao órgão ambiental pode ser um indicativo da preservação ou não de determinada área de proteção. Além de que é inegável, que o aparato legal para punir infrações e o estabelecimento de diversas normativas na criação de áreas de proteção, as especificações de uso e manejo, tem sido um importante aspecto no modelo de proteção, tanto a preservação e intocabilidade de áreas estratégicas quanto à conservação através da utilização controlada dos recursos naturais em áreas específicas (Medeiros e Garay 2006). No entanto, apesar dos indícios de sucesso, a preocupação com a integridade dessas áreas é crescente, visto que só entre 2000 e 2008, 2,25 milhões de hectares foram desmatados dentro dessas áreas (Barreto e Mesquita 2009).

\section{Material e MÉtodos}

A APA Serra do Lajeado está situada estrategicamente no centro do Estado Tocantins, a leste da capital, Palmas, ocupa uma área de 121.415,5 hectares (ha) e está inserida em quatro municípios: Palmas (com 59\% do território da APA), Aparecida do Rio Negro (com 8\%), Tocantínia (com 10\%) e Lajeado (com 23\%). A APA está

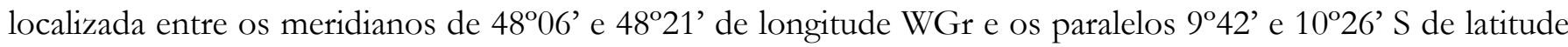
sul (Figura 1), integrando o bioma cerrado brasileiro. Foi criada em 1997, através da Lei no 906 de 20 de maio de 1997 de instância Estadual, pertence à jurisdição da Amazônia Legal e atua como zona de amortecimento do Parque Estadual do Lajeado (PEL). Este Parque foi criado em 2001, com a promulgação da Lei Estadual $\mathrm{n}^{\circ}$ 1.224 de 11 de maio de 2001, e tem a finalidade de proteger os mananciais que abastecem a cidade, a fauna, a flora, características geológicas, geomorfológicas e cênicas, e demais recursos naturais. O PEL representa uma área de 9.931 ha, dentro da APA (Naturatins 2005b).

Para essa pesquisa, os procedimentos metodológicos foram divididos em duas fases: levantamento dos crimes ambientais, ocorridos na área abrangente da APA, e estudo e análises das imagens de sensoriamento remoto. $\mathrm{Na}$ fase do levantamento de crimes ambientais, os dados foram coletados no Instituto Natureza do Tocantins (Naturatins), compreendendo o período de Janeiro de 2001 a Setembro de 2016. As informações foram coletadas por município, dentre os abrangidos pela APA (Aparecida do Rio Negro, Lajeado, Tocantínia e Palmas). As infrações foram classificadas, de acordo com o Sistema Integrado de Gestão Ambiental (SIGA) em categorias de crimes, como: atividade não licenciada, caça, pesca, poluição de solo, represa/barramento, dentre outros. Estes crimes também implicam na não conservação da APA. Para os crimes especificados como “desmatamento" foram identificados a extensão da área desmatada, em hectares, e o local da infração.

Para elaborar os mapas de cobertura vegetal da APA, foram obtidas as imagens dos sensores TM/Landsat 5 de 17/09/2001 e TM/Landsat 8, de 26/06/2016, referente à órbita 222, ponto 67, disponibilizados na base de 
dados United States Geological Survey, web site: 'earthexplorer.usgs.gov'. O processamento digital e a confecção do layout das imagens foram realizados no software SPRING 5.3, no laboratório de geoprocessamento da UFT/Campus Porto Nacional - TO. Com o objetivo de identificar alterações na cobertura vegetal, ocorridas no período investigado, os alvos foram detectados com as composições coloridas obtidas pelo: Landasat5, bandas 3(R) 2(G) 1(B) e Landasat8, bandas 4(R) 3(G) 2(B). Utilizou-se as interpretações visuais e posteriormente classificações digitais supervisionadas para identificar alguns dos pixels pertencentes às classes temáticas, "área desmatada" e "área remanescente". Foi utilizanda a metodologia preconizada por Santos et al. (2010), durante a edição dos mapas obteve-se amostras poligonais de regiões representativas de cada classe, considerando-se a disposição de elementos de textura de uma mesma classe resultando em formas identificáveis, de acordo com o manual SPRING 5.1.2. Para as áreas consideradas desmatadas foi atribuída a cor amarela, e para as áreas remanescentes a cor verde, dessa forma, o aumento da cor amarela no mapa de cobertura vegetal representa maior área desmatada.

Figura 1 - Localização da área de estudo (APA Serra do Lajeado, TO, Brasil).

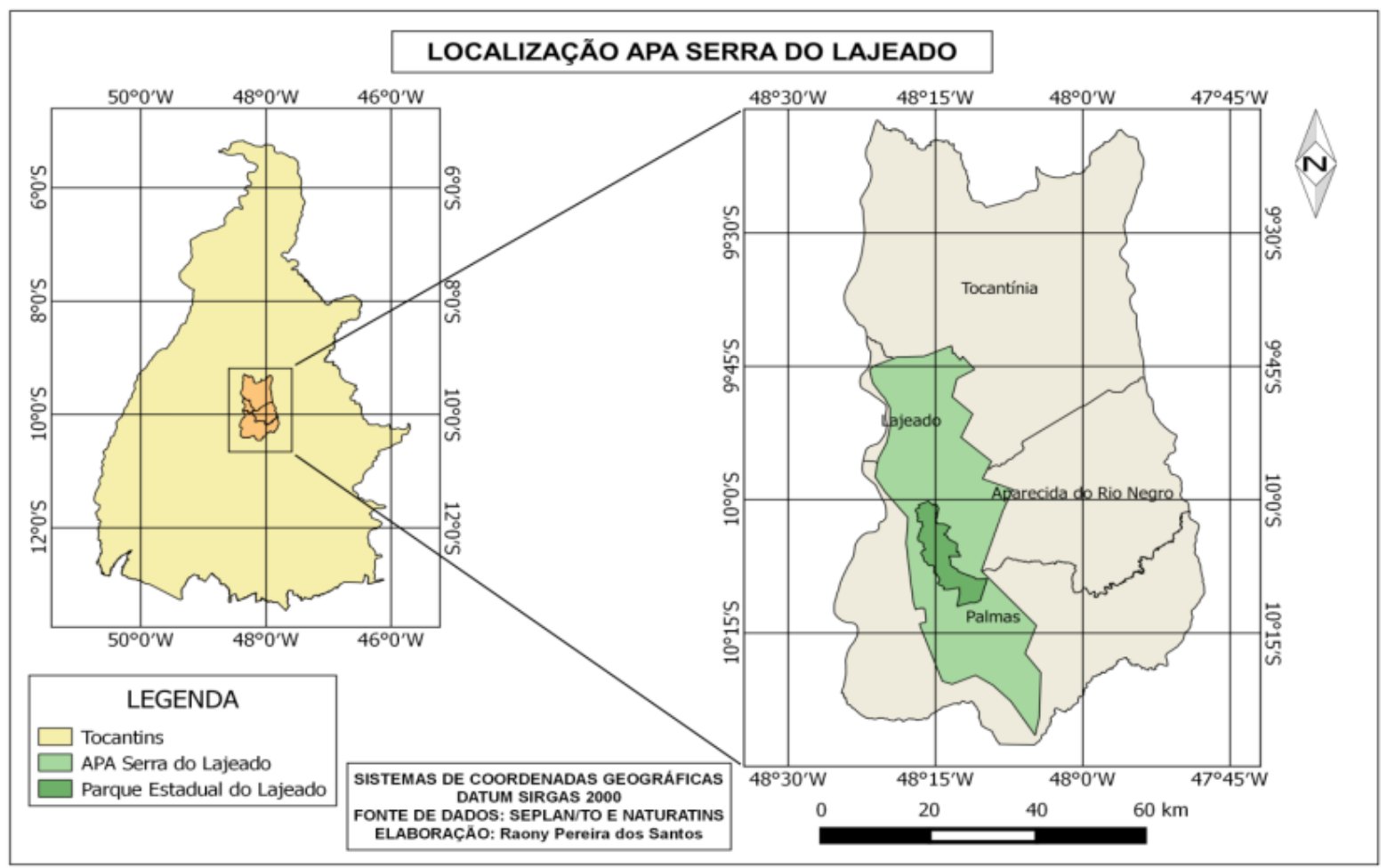

Fonte: Seplan-TO e Naturantins-TO

\section{RESUltados E Discussão}

O resultado obtido na pesquisa, realizada junto ao Naturatins, apresentou 844 autos de infração, distribuídos entre os municípios que integram a APA, no período de Janeiro de 2001 a Setembro de 2016, e 116 destes foram atribuídos ao desmatamento (Tabela 1). Ao separar apenas as infrações relacionadas ao desmatamento, a maior incidência de notificações foi verificada para o município de Palmas. A proximidade da sede do órgão ambiental fiscalizador, bem como, maior estrutura para fiscalização e facilidade de acesso, são fatores que podem contribuir com esse número de notificações, mesmo em pequenas áreas. No entanto, fazendo a relação com o tamanho 
das áreas notificadas nos autos destas infrações, foi identificado 3.016 ha desmatados no entorno da APA, no período de 15 anos, sendo que destes, 1.731 ha foram desmatados em Aparecida do Rio Negro, seguido por Palmas com 1.157 ha, Tocantínia com 127 há, e Lajeado com apenas 1 há (Tabela 1). Apesar do município de Palmas ser responsável pelo maior número de infrações, a maior área desmatada foi registrada para o município de Aparecida do Rio Negro. Cabe destacar que o município de Aparecida do Rio Negro possui a menor área territorial referente à APA Serra do Lajeado (apenas 8\%), assim, os resultados demonstram maior pressão de degradação neste município, necessitando de uma atenção especial de fiscalização nesse município.

Tabela 1 - Quantidade de autos de infrações e área desmatada, no período de Janeiro de 2001 a Setembro de 2016 , por município da APA Serra do Lajeado, Tocantins-Brasil.

\begin{tabular}{cccccc}
\hline Notificações & Palmas & $\begin{array}{c}\text { Aparecida do } \\
\text { Rio Negro }\end{array}$ & Tocantínia & Lajeado & TOTAL \\
\hline Desmatamento & 90 & 15 & 9 & 2 & 116 \\
Outras infrações & 527 & 18 & 21 & 162 & 728 \\
Área desmatada (ha) & 1.157 & 1.731 & 127 & 1 & 3.016 \\
\hline
\end{tabular}

O número de infrações registradas e a área desmatada mostram a necessidade da implementação de um sistema de fiscalização mais rigoroso, com dados precisos, além de uma fiscalização diferenciada, principalmente na área mais impactada, visando contribuir com a garantia da sua conservação. Observou-se também que o número de infrações não corresponde a área total degradada, evidenciada pelas imagens (veremos mais adiante com os dados das imagens). Por isso, mecanismos mais sólidos e perenes de planejamento e investimentos se fazem necessários, uma vez que foi ressaltado que o órgão ambiental tem dificuldade de realizar a fiscalização em áreas mais distantes da capital. Medeiros (2006) destaca que a falta de planejamento de longo prazo e o aporte de recursos têm sido os principais gargalos na consolidação das áreas protegidas brasileiras. Boa parte deste problema advém da fraca tradição brasileira de estabelecer políticas e/ou planos de ação que sejam capazes de trabalhar com cenários desejados, porém realistas, no planejamento desta questão.

Quanto à análise das imagens de satélite, a primeira reflexão a ser destacada é que a APA Serra do Lajeado foi criada em 1997 com área de 121.415,5 ha. Em 2001, início do período analisado nesse trabalho, apresentava uma cobertura vegetal de 91.879 ha remanescente (Figura 2A). No entanto, até Setembro de 2016 a redução foi para 81.817 ha, constatando-se uma supressão de mais de 10.000 ha, ou seja, aproximadamente 11\% da área de cobertura vegetal (Figura 2B).

Esse resultado é preocupante, considerando que o Tocantins é um estado novo, em franca expansão, principalmente na capital e regiões circunvizinhas, exatamente onde se localiza a APA. Destaca-se que as Unidades de Conservação constituem importante instrumento de conservação da diversidade biológica e cultural, pois, além da manutenção da integridade de espécies, populações e ecossistemas, estas áreas contribuem para a manutenção de sistemas e meios tradicionais de sobrevivência de populações humanas, em seu interior e/ou no seu entorno (Carregosa et al. 2015). É importante ressaltar que de acordo com o Decreto Federal no 6.040 de 07 de fevereiro de 2000, as comunidades tradicionais são grupos culturalmente diferenciados e que se reconhecem como tais, possuem formas próprias de organização social, ocupam e usam territórios e recursos naturais como condição para sua reprodução cultural, social, religiosa, ancestral e econômica, utilizando conhecimentos, inovações e práticas gerados e transmitidos pela tradição (Brasil 2000b). No estado do Tocantins há várias etnias 
indígenas e cerca de 2.230 membros da comunidade Xerente, moram no município de Tocantínia (Seplan 2016).

Figura 2 - Mapa de cobertura vegetal - APA Serra do Lajeado (Tocantins - Brasil), imagens obtidas para os anos de A) 2001 B) e 2016.

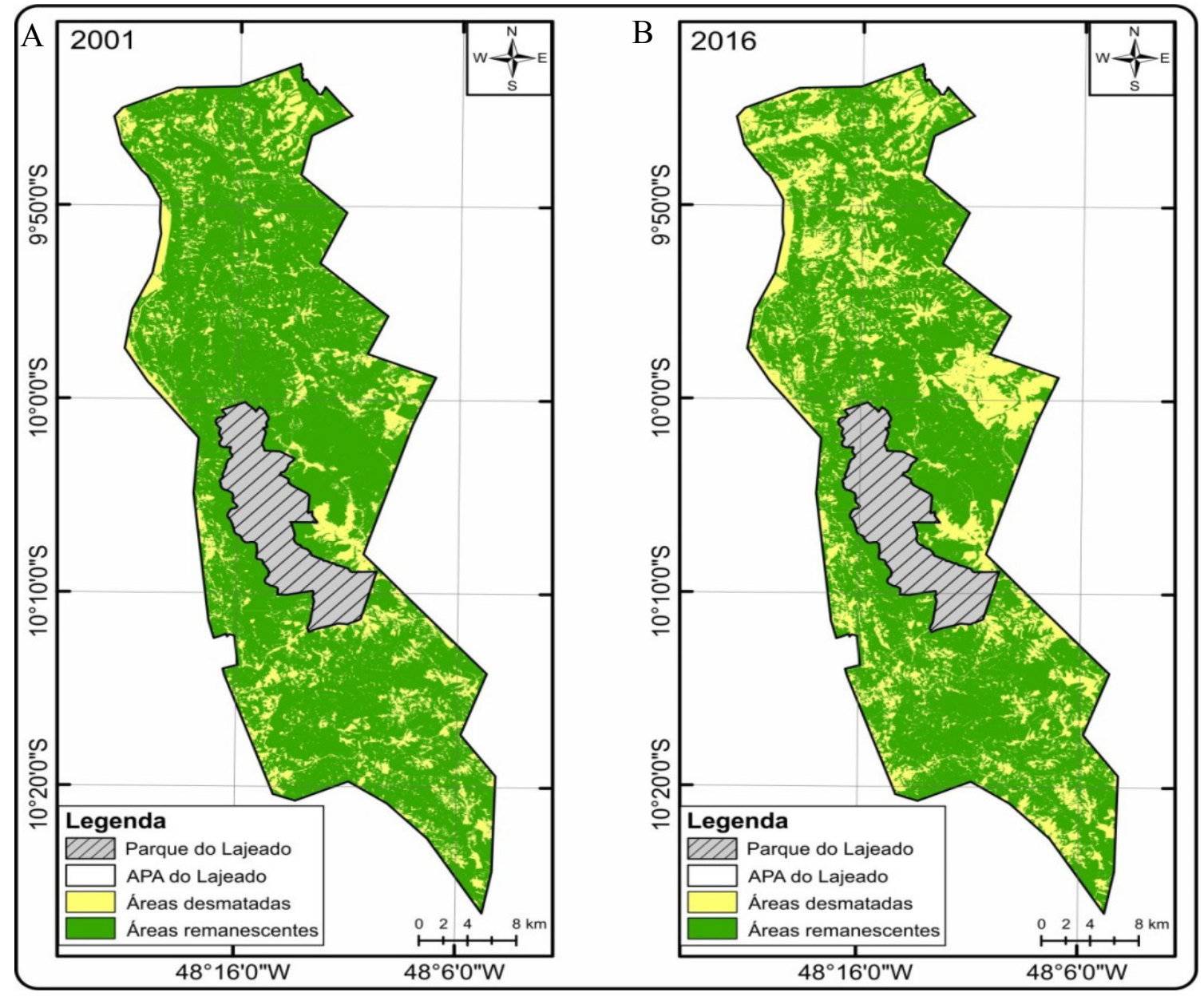

De acordo com o Ministério do Meio Ambiente - MMA, o Cerrado é o segundo maior bioma da América do Sul, ocupando cerca de $20 \%$ do território nacional. Neste espaço territorial encontram-se as nascentes das três maiores bacias hidrográficas da América do Sul (Amazônica/Tocantins, São Francisco e Prata), o que resulta em um elevado potencial aquífero e favorece a sua biodiversidade. No entanto, depois da Mata Atlântica, o Cerrado é o bioma brasileiro que mais sofreu alterações com a ocupação humana, sobretudo com a crescente pressão para a abertura de novas áreas, visando incrementar a produção de carne e grãos para exportação, tem havido um progressivo esgotamento dos recursos naturais da região (MMA 2016). É nesse contexto que a APA Serra do Lajeado está inserida dentro de um bioma de alta importância e com um papel preponderante na conservação da biodiversidade e recursos hídricos. Destaca-se que na abrangência da APA há cerca de 100 cachoeiras inventariadas, 16 ribeirões, grutas, vários córregos e brejos, demonstrando a riqueza única dessa área (Naturatins 2005a). Portanto, considerando que os sistemas são interligados e interdependentes, 11\% de supressão na cobertura vegetal na APA, representam preocupação e indícios da não conservação.

Notório nas imagens, é que houve uma supressão mais evidente na região centro-norte da APA, porém mais acentuada e contínua à leste, que corresponde ao perímetro do município de Aparecida do Rio Negro. Observase essa supressão pela demarcação na cor amarela no mapa da figura 2B. Destaca-se que na área de abrangência de Aparecida do Rio Negro, o desmatamento ocorreu em área contínua, restando pouca cobertura vegetal, 
nos outros municípios aparece mais fragmentado. É possível que o alto índice de desmatamento observado nessa área esteja relacionado com o perfil econômico do município. De acordo com o Instituto Brasileiro de Geografia e Estatística (IBGE 2014), aproximadamente 50\% do Produto Interno Bruto do município é oriundo de atividades agropecuárias. Além disso, tem se destacado e recebido incentivo para a produção de grãos; de acordo com o Instituto de Pesquisa Econômica Aplicada (IPEA 2010), o plantio de soja na região do Tocantins, tem aumentado significativamente, especialmente em Aparecida do Rio Negro, que cresceu de 8.400 para mais de 11.700 toneladas anuais, até o ano de 2010, ocupando mais áreas para plantio. A opção por investimento na expansão agrícola, sem dúvida, ocasiona maior pressão para supressão de áreas da APA.

A APA foi dividida em áreas e tipo de utilização, para delimitar as atividades permitidas com foco na manutenção da preservação. De acordo com o Plano de Manejo da APA Serra do Lajeado o primeiro zoneamento da área foi elaborado pelo Naturatins, em 1998, quando a área do parque ainda integrava a APA, e foram estabelecidas sete zonas ambientais. Em decorrência das alterações do uso e ocupação do solo nos anos seguintes, tais como: expansão da área urbana de Palmas; pavimentação da rodovia TO 010; criação do Parque Estadual do Lajeado; construção da Usina de Lajeado; abertura de novas estradas, dentre outros, houve a redefinição do zoneamento da APA (Naturatins 2005b).

Com a criação do Parque Estadual do Lajeado em 2001, considerado área-núcleo, hoje individualizada como Zona de Preservação da Vida Silvestre, houve a subtração dessa área e novo zoneamento da APA. Reduziu-se para duas: Zona de Preservação e Zona de Conservação; a primeira foi denominada de Zona Serrana (25,5\%), enquanto a segunda foi subdividida em função das suas especificidades: Zona de Recuperação (2,9\%), Zona de Uso Especial (15,6\%), Zona de Uso Extensivo (23,7\%) e Zona de Uso Intensivo (32,3\%) (Naturatins 2005b). O novo zoneamento aumentou para $56 \%$ a área de uso intensivo e extensivo, o que demonstrou uma tendência de tornarem a maior parte da área, em utilitária para o uso, ainda que com restrições estabelecidas no zoneamento.

Para identificar a zona que ocorreu maior degradação, foi realizada análise das imagens detalhando os tipos de zona de uso e localização, com a cobertura vegetal (Fig. 3). Ao observar o mapa de cobertura vegetal (Fig. 3A), comparado com a área de zoneamento do plano de manejo da APA (Fig. 3B), verifica-se que houve redução da vegetação em áreas da zona de preservação e de conservação. A zona de preservação está condicionada à observância de normas de controle rigorosas, já a zona de conservação, permite a ocupação do território em condições adequadas de manejo e utilização dos recursos naturais (Naturatins 2005b).

Observa-se que houve maior supressão, nas zonas predominantemente de uso intensiva e extensiva, localizadas principalmente em Palmas, Aparecida do Rio Negro e Tocantínia. Porém, embora classificadas na mesma zona de uso, apresentaram características diferentes. Palmas apresentou desmatamento de forma fragmentada, destaca-se que o Parque Estadual de Lajeado, é uma área de proteção integral e que a APA funciona como zona de amortecimento, portanto, o desmatamento na APA ameaça também a preservação do Parque. Ressalta-se ainda, que houve aumento da cobertura vegetal na zona de recuperação, no município de Palmas.

A área de Aparecida do Rio Negro apresentou desmatamento em grande área contínua, mesmo sendo área de uso extensivo e intensivo, não justifica tamanha supressão de cobertura, uma vez que nessas áreas existem restrições e procedimentos a serem utilizados para uso. Um fato que chama a atenção é que neste município está contida a menor área da APA (8\%), com relação aos outros municípios, e é o que mais demonstra área contínua desmatada (Fig. 3), corroborando com os dados da tabela 1.

Tocantínia não apresentou supressão de cobertura vegetal significativa, as áreas se mantiveram praticamente 
estáveis desde o início do período analisado. É um contraponto ao que ocorre em Aparecida do Rio Negro, sendo que ambos os municípios apresentam áreas de uso intensivo e extensivo. Portanto, o município de Tocantínia apresentou-se mais preservado, com as mesmas especificidades de uso. Vale ressaltar que este município tem grande área ocupada por povos indígenas, o que pode ser reflexo da forma de uso mais apropriado à conservação da natureza. Kantek et al. (2009) destaca que é imprescindível que se monitore de maneira eficiente essas áreas, vindo a utilizar as populações tradicionais, como aliados, contra a ação impactante da remoção total da cobertura vegetal original, de regiões de florestas sob a ação de especulações imobiliária, agrícola e industrial.

Figura 3 - Mapa de cobertura vegetal, com descrição das divisas dos municípios, para o ano de 2016 (A); e mapa de zoneamento, elaborado conforme o plano de manejo (B) da APA Serra do Lajeado.
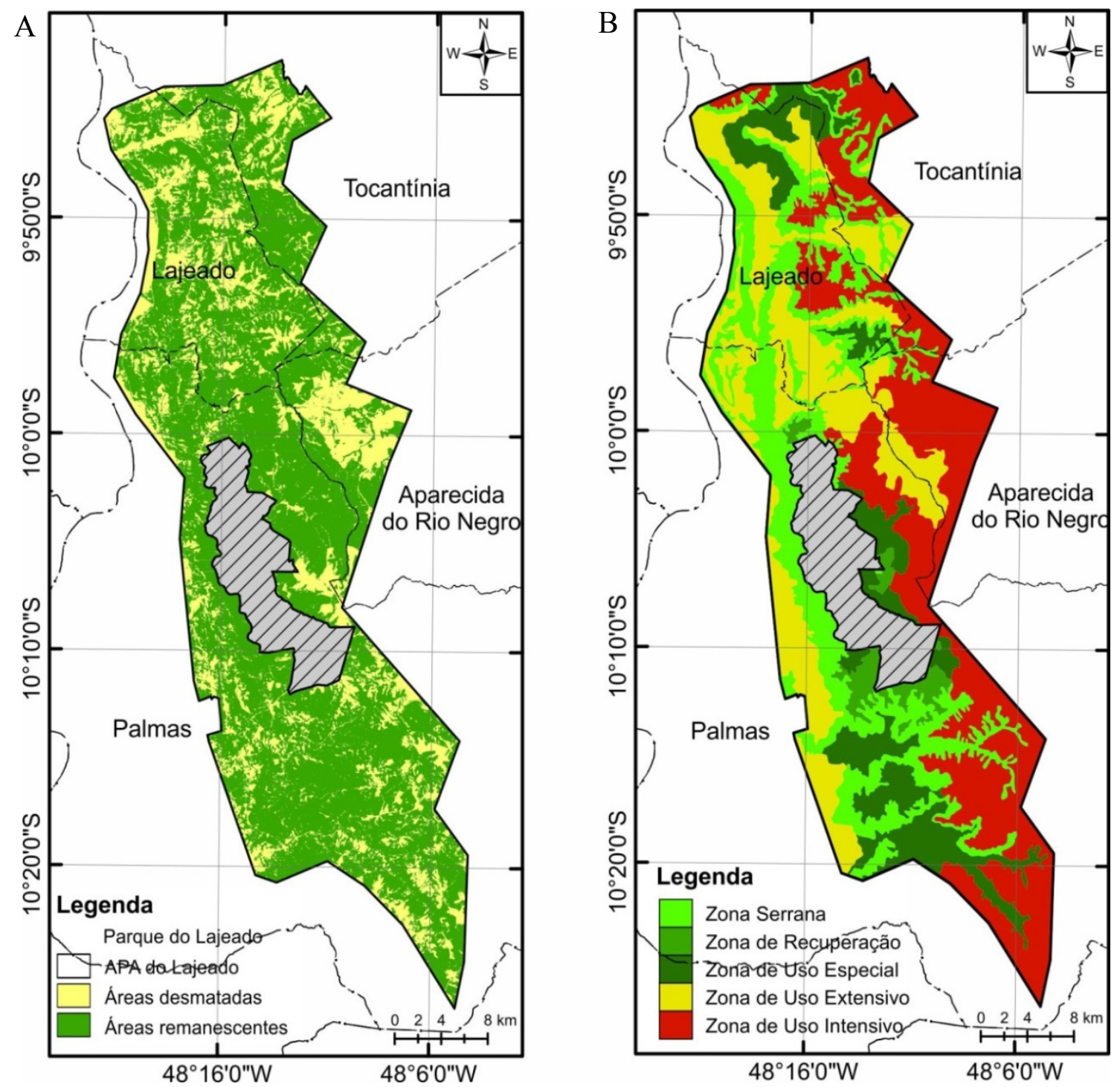

Lajeado apresenta praticamente todas às zonas de uso, preservação e conservação (intensivo, extensivo e uso especial), com exceção da zona de recuperação. Neste município a supressão ocorreu mais fragmentada, possivelmente por essas diversas formas de uso. Sabe-se que essas zonas vêm sofrendo pressões devido à proximidade da capital, tanto pela especulação imobiliária, como pela expansão agrícola. Independentemente do tipo de zona de uso, as atividades precisam ser autorizadas pelo órgão ambiental, necessitando inclusive de estudos de impactos ambientais, respeitando o que foi definido no Plano de Manejo da área protegida.

Nesse sentido, é coerente que os órgãos responsáveis pela gestão e fiscalização das UCs estabeleçam 
integradamente ao plano de manejo das áreas protegidas, o planejamento territorial das áreas em seus entornos, além de gozar de autoridade para autorizar, ou vetar, a instalação de empreendimentos e modificações nos padrões de uso do solo e ocupação dessas áreas (Beiroz 2015). Veríssimo et al. (2011) complementam que os indicadores de gestão e pressão relatados na maioria dos estudos dessas áreas, apontam que além de investir na implementação e fiscalização das Áreas Protegidas, é preciso aumentar o número de planos de manejo concluídos e de conselhos gestores formados, e ainda, reforçar e qualificar o escasso quadro de funcionários lotados nas UCs.

De uma forma geral, a APA Serra do Lajeado tem sofrido alterações na sua cobertura vegetal, bem como, pressões com o crescimento e expansão do agronegócio crescente nos últimos anos, nas cidades em que se localiza. Segundo estudos do IPEA (2010), os Estados do Amapá e Tocantins foram os que mais aumentaram sua participação na área plantada brasileira, no período de 1994 a 2010. Destaca-se que o Tocantins tinha cerca de 600 mil ha de área plantada em 2006 e passou para mais de 654 mil ha, em 2010, com fortes tendências para o aumento significativo nos próximos anos com a consolidação do Matopiba, projeto de fronteira agrícola para a região.

Além da ameaça da expansão agrícola, Peixoto (2006) alerta que a expansão da malha urbana, via parcelamento do solo, é a produção de uma mercadoria de valor crescente no mercado, tendo em vista a manutenção dos fluxos migratórios que se dirigem às cidades, além dos investidores imobiliários. No Tocantins, a valorização das áreas e dos diversos empreendimentos imobiliários, sobretudo nas áreas do entorno da capital, tem alcançado grandes proporções.

\section{ConClusões}

Com essa pesquisa foi possível identificar que a APA Serra do Lajeado, apresenta redução na cobertura vegetal, observada tanto na análise dos autos de infração quanto no estudo das imagens. A maioria da supressão ocorreu nas zonas de uso intensivo e extensivo, com características de uso irregular, principalmente no município de Aparecida do Rio Negro, região crescente na produção de grãos e agropecuária. No entanto, também se destaca a dificuldade do órgão em fiscalizar os diversos pontos que compõem a APA, uma vez que a área de infrações notificadas pelo órgão ambiental ainda é menor que a supressão identificada nas imagens. Durante a pesquisa dos autos, obteve-se dificuldade para o manuseio dos dados sistematizados, pois a maioria estava em planilhas simples, o que pode ser um fator complicador para acompanhar as reincidências das infrações.

Por fim, os resultados aqui apresentados indicam a necessidade de mais estudos para avaliar as causas de supressão vegetal e discutir possíveis contribuições com as políticas de conservação, no entanto, o objetivo desse trabalho foi alcançado, o de avaliar a conservação da APA. Nesse viés, demonstra-se o desafio que é manter áreas protegidas, diante de tantas ameaças no seu entorno e no contexto atual brasileiro.

\section{REFERÊNCIAS}

Barreto P, Mesquita M. 2009. Como prevenir e punir infrações ambientais em Áreas Protegidas na Amazônia. Belém: Imazon, 2009. 54 p. 
Beiroz H. 2015. Zonas de amortecimento de Unidades de Conservação em ambientes urbanos sob a ótica territorial: reflexões, demandas e desafios. Desenvolvimento e Meio Ambiente. (35): 275-286.

Brasil. 1981. Lei No 6.902, de 27 de abril de 1981. Dispõe sobre a criação de Estações Ecológicas, Áreas de Proteção Ambiental e dá outras providências. Disponível em: < http://www.planalto.gov.br/ ccivil 03/leis/ L6902.htm>. Acesso em: nov.2016.

Brasil.1988. Constituição da República Federativa do Brasil. Brasília, DF: Senado Federal.

Brasil. 1998. Lei 9605, de 12 de fevereiro de 1998. Dispõe sobre as sanções penais e administrativas derivadas

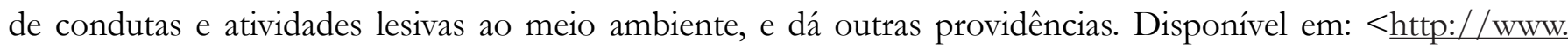
planalto.gov.br/ccivil 03/leis/L9605.htm>. Acesso em 10 de outubro de 2016.

Brasil. 2000a. Lei Federal No 9.985, de 18 de julho de 2000. Regulamenta o art. 225, \1o, incisos I, II, III e VII da Constituição Federal, institui o Sistema Nacional de Unidades de Conservação da Natureza - SNUC e

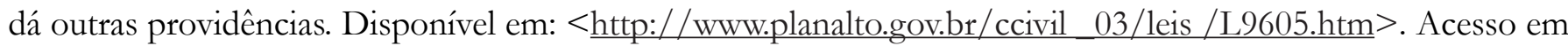
novembro de 2016.

Brasil. 2000b. Decreto Federal $\mathbf{n}^{\mathbf{0}} \mathbf{6 . 0 4 0}$ de 07 de fevereiro de 2000. Institui a Política Nacional de Desenvolvimento Sustentável dos Povos e Comunidades Tradicionais. Disponível em: $<\underline{\text { http://www.planalto. }}$ gov.br/ccivil 03/ ato2007-2010/2007/decreto/d6040.htm>. Acesso em abr.2018.

Brasil. 2006. Decreto 5.758, de 13 de Abril de 2006. Institui o Plano Estratégico Nacional de Áreas Protegidas - PNAP, seus princípios, diretrizes, objetivos e estratégias, e dá outras providências. Disponível em: $<\underline{\text { http: } / / ~}$ www.mma.gov.br/estruturas/205/arquivos/ planonacionaareasprotegidas 205.pdf > Acesso em nov. 2016.

Brasil. 2008. Decreto $\mathbf{N}^{\mathbf{0}} \mathbf{6 . 5 1 4}$, de 22 de julho de 2008. Dispõe sobre as infrações e sanções administrativas ao meio ambiente, estabelece o processo administrativo federal para apuração destas infrações, e dá outras providências. Disponível em: < http://www.planalto.gov.br/ccivil 03/ato2007-2010/2008/decreto/d6514.htm>. Acesso em nov.2016.

Carregosa EA, Silva SLC, Kunhavalik JP. 2015. Unidade de Conservação e comunidade local: uma relação em construção. Desenvolvimento e Meio Ambiente (35): 305-319.

Dudley N. Guidelines for applying protected area management categories. Switzerland: IUCN, 2008. 106 p.

IBGE.2014.InstitutoBrasileirodeGeografiaeEstatísticas. CadastroCentraldeEmpresas..Disponívelem: $<\underline{\text { http:// }}$ www.cidades.ibge.gov.br/painel/economia.php?lang $=\&$ codmun $=70110 \&$ search=tocantins $\mid$ aparecida-do-rionegro $\mid$ infogr $\%$ E1 ficos:-despesas-e-receitas-or\%E7ament\%E1rias-e-pib $>$ Acesso em 05 de novembro de 2016.

IPEA. 2010. Instituto de Pesquisa Econômica Aplicada. Base de Dados - Ipeadata. Produção agrícola por

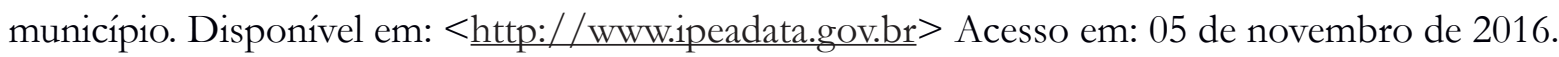

Kantek RT, Sautter KD, Michaliszyn MS. 2009. Impactos ambientais na Área de Proteção Ambiental (APA) de Guaratuba, Paraná, Brasil, sob o ponto de vista de moradores tradicionais. Sociedade \& Natureza. 21 (2): 
$39-56$.

Medeiros R. 2006. Evolução das tipologias e categorias de Áreas protegidas no Brasil. Ambiente \& Sociedade. $9(1): 41-64$.

Medeiros R, Garay I. 2006. Singularidades do sistema de áreas protegidas para a conservação e uso da biodiversidade brasileira. In: Garay, I. e Becker, B. (orgs.) Dimensões Humanas da Biodiversidade: O desafio de novas relações sociedade-natureza no século XXI. Petrópolis: Editora Vozes, p. 159 - 186.

MMA. 2016. Ministério do Meio Ambiente. Conceito de Unidades de Conservação. Disponível em: $<\underline{\text { http: } / /}$ mma.gov.br/areas-protegidas> Acesso em 10 de outubro de 2016.

Naturatins. 2005a. Plano de Manejo APA Serra do Lajeado. Palmas - TO, 2005b. Disponível em: <http://www. gesto.to.gov.br/uc/52/documentos/>Acesso em: 10 de Outubro de 2016.

Naturatins. 2005b. Plano de Manejo Parque Estadual do Lajeado. SEPLAN. DBO Engenharia: Palmas. Disponível em: < http://www.gesto.to.gov.br/site media/upload/gestao/ documentos/PEL Plano de Manejo 2005. pdf>. Acesso em: 10 de outubro de 2016.

Peixoto MCD. 2006. Expansão urbana e proteção ambiental: um estudo a partir do caso de Nova Lima/MG. In: COSTA, H. S. de M.(Org.). Novas periferias metropolitanas: a expansão metropolitana em Belo Horizonte: dinâmica e especificidades no Eixo Sul. Belo Horizonte: C/Arte, p. 1-13.

Rezende LP. 2007. Avanços e contradições do licenciamento ambiental de barragens hidrelétricas. Belo Horizonte: Fórum. 269 p.

Rylands AB, Brandon K. 2005. Unidades de conservação. Megadiversidade. 1 (1): 27-35.

Seplan. 2016. Secretaria do Planejamento e Orçamento - TO. Zoneamento Ecológico-Econômico. Diagnóstico da Dinâmica Social e Econômica do Estado do Tocantins: Populações Tradicionais. Palmas: Seplan, 2016. 159 p., Ilust.

Santos AR, Peluzio TMO, Saito NS. 2010. Spring 5.1.2: passo a passo: aplicações práticas. Alegre-ES: CAUFES. 155 p.

Teixeira MG, Venticinque EM. 2014. Fortalezas e fragilidades do Sistema de Conservação Potiguar. Desenvolvimento e Meio Ambiente. 29: 113-126.

Tocantins. 1997. Lei no 906 de 20 de maio de 1997. Cria a Área de Proteção Ambiental - APA Serra do Lajeado

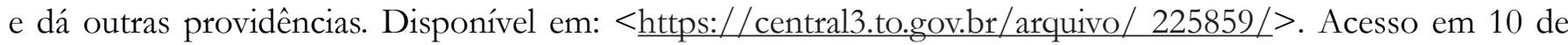
outubro de 2016.

Verissimo A, Rolla A, Vedoveto M.; Furtada SM. (org.). 2011. Áreas protegidas na Amazônia Brasileira: avanços e desafios. São Paulo: Instituto Socioambiental. 90 p. 